\title{
Downblending Contaminated Radioactive Wastes
}

\author{
Leong Ying ${ }^{1}$, Robert Brenna ${ }^{1}$, Richard Yuen ${ }^{1}$, Cory Hoskins ${ }^{2}$ \\ ${ }^{1}$ KLYTEC, New Jersey, USA \\ ${ }^{2}$ Advanced TENORM, Kentucky, USA
}

\section{Email address:}

leong.ying@klytec.com (L. Ying), robert.brenna@klytec.com (R. Brenna), richard.yuen@klytec.com (R. Yuen), choskins@advtenorm.com (C. Hoskins)

\section{To cite this article:}

Leong Ying, Robert Brenna, Richard Yuen, Cory Hoskins. Downblending Contaminated Radioactive Wastes. International Journal of Environmental Monitoring and Analysis. Special Issue: Clean Methods and Technologies for Hydraulic Fracturing.

Vol. 3, No. 2-1, 2015, pp. 11-14. doi: 10.11648/j.ijema.s.2015030201.13

\begin{abstract}
Dilution is the mixing of radioactive waste with non-radioactive material, whereas downblending is the mixing of high-level radioactive waste with low-level radioactive waste. These processes have been applied predominantly at nuclear sites as part of the decontamination procedures for the disposal of blended wastes in licensed facilities. Proper health and safety assessments should be carried out as part of the processes and procedures of diluting or downblending radioactive waste before disposal to ensure minimal risks to the general public and environment. Hydraulic fracturing for the exploration of oil and natural gas can bring NORM materials to the surface, and the processing of these wastes can further enhance the radiological concentration of these Technologically Enhanced Naturally Occurring Radioactive Material (TENORM). Current regulations and industry practices are investigating the feasibility of incorporating dilution or downblending as a means of waste predisposal processing and management of hydraulic fracturing produced TENORM wastes.
\end{abstract}

Keywords: Dilution, Downblending, Hydraulic Fracturing, TENORM, Gamma Spectroscopy

\section{Introduction}

The U.S. Nuclear Regulatory Commission (NRC) is charged with supervision for the safety of nuclear power production and other civilian uses of radioactive nuclear materials. Nuclear regulations are outlined in the Code of Federal Regulations (CFR) Title 10 [1]. NRC issued a report on the potential environmental impacts of various handling methods for low-level radioactive waste (LLRW) including blending, long-term storage, direct disposal and volume reduction [2]. NRC's stated position on blending is based on performance and results. Blended waste must meet the limits on radiation exposures at the disposal facility and limits on how much the radioactive concentration may vary. Regulatory guidance of blended waste to ensure safe disposal will include how uniform or well-mixed the waste must be. NRC safety requirements state limits of 100 milli-rems (1 milli-Sivert) per year for members of the general public (which is approximately a third of average annual dose from nature) and 5,000 milli-rems (0.05 Sivert) per year for nuclear workers. Storage of LLRW requires an NRC or Agreement State license, which requires the waste to be stored in a manner that maintains radiation dose to workers and members of the public below NRC-specified levels. LLRW is packaged in containers appropriate to its level of hazard, and some wastes require shielding with lead, concrete or other materials. There are currently two disposal facilities that accept broad range of low-level wastes; located in Barnwell (South Carolina) and Richland (Washington). NRC has also licensed Envirocare to operate a facility near Clive (Utah) for disposal of low-level uranium and thorium mill tailings. Figure 1 illustrates the various sources of disposed LLRW.

For disposal of high-level waste the containers must maintain its integrity for 300 to 1,000 years, and must be retrievable for 50 years after waste emplacement begins. In a nuclear power plant, spent fuel is considered high-level radioactive waste (HLRW), and even 10 years after removal from a reactor, the radiation dose a meter away from a typical spent fuel assembly can exceed 20,000 rems per hour (a dose of 5,000 rems would be expected to cause death within one week of exposure). Currently most spent nuclear fuel rods are stored in water-pools at individual reactor sites under at least 20 feet of water. NRC also license an alternative above ground dry storage method, whereby spent fuel is immersed by inert gas inside a cask container. The cask can be made of 
concrete or metal. Up to seventeen US nuclear power plants are currently storing spent fuel using the dry storage option.

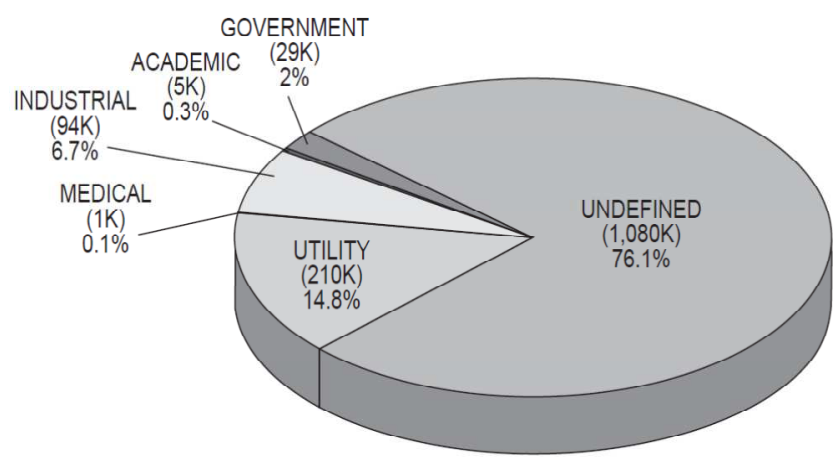

Total Amount Received -

1,419 thousand cubic feet

Figure 1. Sources of low-level radioactive waste received at U.S. disposal facilities in 1998.

Mill tailing wastes are generated during the milling of ores for the extraction of uranium and thorium. These wastes have relatively low concentrations of radioactivity with long half-lives. Tailings contain daughter decay radium isotopes that in turn decays to radon gas, thorium and small residual amounts of uranium not extracted during the milling process. NRC regulates milling and disposal of tailing in non-Agreement States, while State agencies are responsible for regulations in Agreement States where the agreement specifically includes tailings. A mobile sodium-iodide (NaI) scintillation detector was successfully used as an on-site laboratory to estimate concentrations of radionuclides in soil during cleanup activities at a former uranium mill site. The NaI gamma spectroscopy system was calibrated against a high-purity germanium (HPGe) laboratory-based system, and statistical comparisons demonstrate the on-site testing facility achieved similar levels of accuracy and precision [3].

In the drilling of deep wells for exploration of oil and natural gas, the extracted cores constituting the drill cuttings can bring to the surface the same NORM radioactive materials as the mill tailing wastes from uranium mining. To extract hydrocarbon fuels from tightly bound shale deposits, hydraulic fracturing (fracking) is employed. A composition mixture of water, sand and chemicals are pumped at high-pressures into the drilled wells to fracture the rocks and force out the oil or natural gas. However, in the process the surrounding rocks can also liberate radioactive NORM into the produced wastewaters that returns to the surface with the desired hydrocarbons. Hydraulic fracturing wastes can therefore be associated with chemical and radiological contaminations [4]. A similar mobile NaI testing system referenced earlier to on-site testing of uranium mill tailings was developed for quantification of Ra226 and Ra228 of hydraulic fracturing produced wastes [5]. The types of radiological contaminations deposited along the production equipment can vary dependent on whether the site is for exploration of oil or gas, and this can impact the waste management practices for decontaminating such a site [6]. The author acting as technical advisor to an organization recently released new suggested State regulations on oil and gas industry produced TENORM wastes [7].

Radioactive drill cuttings and produced wastewaters are regulated by each State. Typical lower permitted levels of concentrated activities for combined Ra226 and Ra228 in solid wastes are $5 \mathrm{pCi} / \mathrm{g}(185 \mathrm{~Bq} / \mathrm{kg})$ above background. Low concentrated wastes are disposed into landfill sites, but wastes above local State regulated levels have to be sent to licensed LLRW disposal sites. Although not yet permitted, several States are reviewing the feasibility of dilution or blending of radioactive wastes down to levels that would allow for local landfill disposal. Ying has filed a new patented invention for assessing and diluting contaminated radioactive materials [8].

\section{Radioactive Waste Management}

There are three general classifications to the predisposal management of radioactive wastes [9].

\subsection{Concentrate and Contain}

Reduction in the volume of wastes followed by confinement of the radionuclide contents to prevent or substantially reduce dispersion into the surrounding environment. This typically involves holding of waste in a storage facility or the emplacement of waste in a disposal facility. The radioactive wastes will be required to be processed so that it can be safely contained within a storage or disposal facility. Produced wastewaters from hydraulic fractured sites are typically stored temporary on-site in storage pools or tanks. Some on-site processing may take place to extract and reuse the chemicals and water, which will likely increase the TENORM concentration in the remaining wastes. In certain situations where local regulations permit, the accumulated wastes can be re-injected back down into the deep wells after exploration of the desired hydrocarbon fuel have been exhausted. In general the wastes are transported to wastewater treatment plants (WWTP) that filters and concentrate the TENORM into solid wastes for final disposal at landfill sites.

\subsection{Delay and Decay}

This method involves the storage of wastes until the necessary reduction in radioactivity concentrations has occurred from the natural decays of the radionuclides contained in the waste. The NORM and TENORM radionuclides produced from hydraulic fracturing have natural decay half-lives ranging in the thousands and millions of years, so it is impractical to adopt this as a predisposal technique. For medical isotopes that typically have short half-lives of a few days, the contaminated wastes can be temporary stored securely in hospitals after use to allow the radiation to decay sufficiently that the wastes can then be 
disposed as either non-radioactive or LLRW.

\subsection{Dilute and Disperse}

The discharging of effluent wastes into the environment such that the conditions and processes ensure the radionuclide concentrations are reduced to acceptable levels to neutralize the radiological impact of the released materials. This is a legitimate practice in the management of radioactive wastes if performed within authorized limitations established by the regulatory agencies.

\subsection{Radiation Monitoring}

Enforcement of regulations is only as effective as the means to detect and quantify violations. Traditionally the sampling of radioactive TENORM wastes from oil and gas producers and waste treatment plants have been performed by complex radiochemical analysis in certified laboratories. The costs and long wait periods for receiving test results have been prohibitive to allow for meaningful and effective controls of the produced waste streams. Recent research has also indicated that for high salinity brine wastes produced from hydraulic fracturing, the radiochemical methods can generate erroneous results when compared to gamma spectroscopic methods [10].

For rapid screening of radioactive wastes there are two generalized detection systems deployed, either the type that performs counting of incident radiation without identifying the source, or spectroscopic detectors that can count and measure the incident energy of the radiation thereby identifying the signature of the emitting radionuclide source. An example of the former is an inexpensive gas-filled Geiger-Muller detector, which with an installed thin-walled window can detect alpha, beta, x-ray and gamma radiation. When properly calibrated, the device can provide both count and dose rates information. In real applications these counting detectors can perform as survey meters scanning the surface of radioactive wastes. However, since these surveys are internally non-invasive and typically source-to-detector distance variable it is not possible to determine the radioactivity concentration of the inspected waste.

Certain scintillation detectors (such as $\mathrm{NaI}$ ) or semiconductor detectors (such as HPGe) when matched to appropriate electronics (amplifiers and multi-channel analyzers) are able to determine the energy of the incident radiation. Generally these expensive spectroscopic detectors are housed with thick-walled windows that do not allow for the penetration of alpha or beta charged particles, and therefore can only perform x-ray or gamma spectroscopy. Figure 2 illustrates the difference in defining radiation emitted from electron excitations in the outer atomic shells (x-ray) and those emitted from internal nuclear decays (gamma). For identifying specific radionuclides in hydraulic fracturing TENORM wastes, it is the matching gamma energies that are used in the analysis. With appropriate energy and efficiency calibrations of the detector system, and volumetric mass measurement of the tested samples, it is possible to quantify the precise activity concentration of the sampled radioactive waste [11].

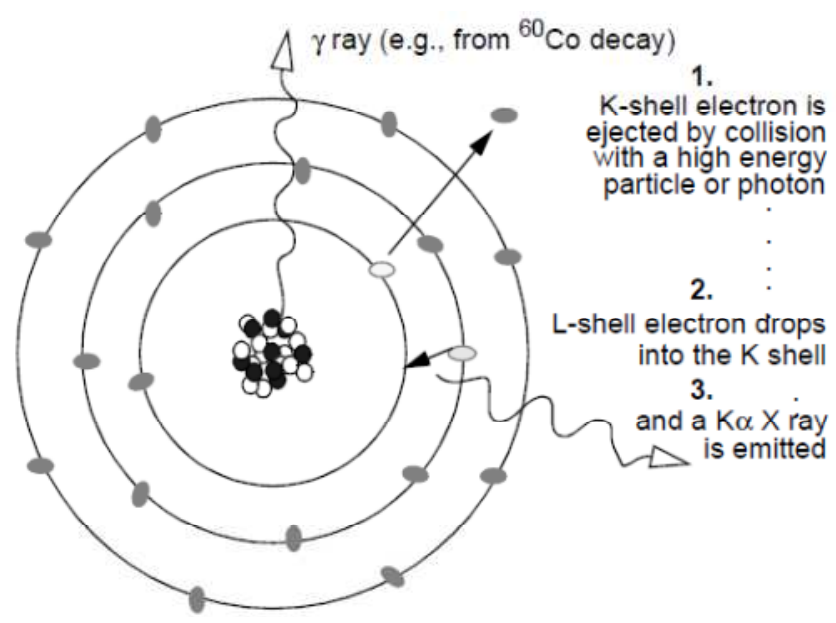

Figure 2. Schematic representation of gamma and $x$-ray generated radiation.

\section{Blending}

\subsection{Hazardous Mixture}

The mixture and derived-from rules regulate the management of mixtures of hazardous (includes non-radioactive) wastes [12]. The mixture rule operates differently for listed and characteristic hazardous wastes. When a Listed hazardous waste is combined with a nonhazardous waste, the resulting mixture is still considered to be a listed waste regardless of any mixing, treatment or other changes. When a Characteristic waste is combined with a nonhazardous waste, the mixture must be determined to have one or more hazardous characteristics; otherwise it is not generally subject to the federal Resource Conservation and Recovery Act (RCRA) requirements that regulates solid waste disposal. However, Local and State regulations must still be satisfied prior to land disposal of the characterized waste.

\subsection{Fissile Material Downblending}

U.S. Department of Energy (DOE) conducted research at Oak Ridge National Laboratory for downblending U-233 suitable for transportation of the processed mixture to a licensed disposal facility [13]. The process involves extracting and dissolving the U-233 in nitric acid and blending with depleted uranyl nitrate. The downblended mixture is then dried and package in containers suitable for transportation to disposal facilities. Secondary wastes from the blending process will be similarly package and disposed of based on its appropriate hazardous waste classifications. The purpose of the downblend operations is to reduce the concentration of fissile materials to less than $0.96 \% \mathrm{U}-235$ equivalent ( $1 \mathrm{~g}$ of $\mathrm{U}-233$ has a fissile equivalent to $1.4 \mathrm{~g}$ U-235). Below $0.96 \%$ concentration the material would be non-weapons usable and would not pose criticality concerns. 


\subsection{Contaminated Soil Remediation}

U.S. Environmental Protection Agency (EPA) produced a summary report on the various technologies demonstrated to be effective for treatment of radiologically contaminated earth media [14]. One of the described methods is the stabilization and solidification processes. The ex-situ techniques involve removing the contaminated soil and machine-mixing with solidifying agent to trap the radionuclides in place prior to disposal of the resultant mixture. Although not a direct dilution or blending process, it does involve the mixing of the radioactive waste with non-radioactive materials to form a composite mixture which in principle with the increased volumetric mass should have lower activity concentrations. $\mathrm{NRC}$ released a policy issue following research evaluation of the use of intentional mixing of contaminated soil, and concluded on a case-by-case basis is consistent with current commission practice [15].

\section{Conclusion}

The technologies and methods exist that when properly used under regulatory guidelines can provide the means to reduce the contaminated concentration of radioactive wastes produced by hydraulic fracturing to safe levels for suitable disposal. The process of determining the appropriate treatments require a detailed measurement of radioactivity of the contaminated wastes or sites. Modeling of the dose or activity concentrations based on measurement and analysis can offer a predisposal assessment whether dilution or downblending is a feasible decontamination technique acceptable within regulated domains.

\section{References}

[1] United States Nuclear Regulatory Commission, 10 CFR, NRC Library: http://www.nrc.gov/reading.rm/doc-collections/cfr/

[2] United States Nuclear Regulatory Commission, Final comparative environmental evaluation of alternatives for handling low-level radioactive waste spent ion exchange resins from commercial nuclear power plants, Federal Register, vol. 78, no. 188,2013 , pp. 59729-59731.

[3] R. Whicker, M. Whicker, J. Johnson and B. Meyer, Mobile soils lab: on-site radiological analysis supporting remedial activities, Health Physics: The Radiation Safety Journal, vol. 91, no. 2, 2006, pp. S24-S31.
[4] N. R. Warner, C. A. Christie, R. B. Jackson and A. Vengosh, Impacts of shale gas wastewater disposal on water quality in western Pennsylvania, Environmental Science and Technology, vol. 47, 2013, pp. 11849-11857.

[5] L. Ying, F. O'Connor, TENORM radiological survey of Utica and Marcellus shale, Applied Radiation and Isotopes, vol. 80, 2013, pp. 95-98.

[6] M. Peroni, V. Mulas, E. Betti, L. Patata and P. Ambrosini, Decommissioning and remediation of NORM/TENORM contaminated sites in oil and gas, Chemical Engineering Transactions, vol. 28, 2012, pp. 181-186.

[7] Conference of Radiation Control Program Directors, E-42 Task Force Report: Review of TENORM in the oil and gas industry, 2015.

[8] L. Ying, Method and apparatus for assessing and diluting contaminated radioactive materials, 2015, US Patent pending 14816554.

[9] International Atomic Energy Agency, Predisposal management of radioactive waste, General Safety Requirements Part 5, 2009.

[10] A. W. Nelson, D. May, A. W. Knight, et al., Matrix complications in the determination of radium levels in hydraulic fracturing flowback water from Marcellus shale, Environmental Science and Technology Letters, vol. 1, 2014, pp. 204-208.

[11] L. Ying, F. O'Connor and J. Stolz, Scintillation gamma spectrometer for analysis of hydraulic fracturing waste products, Journal of Environmental Science and Health, Part A, vol. 50, 2015, pp. 499-503.

[12] United States Environmental Protection Agency, Land disposal restrictions: summary of requirements, Offices of Solid Waste and Emergency Response \& Enforcement and Compliance Assurance, EPA 530-R-01-007, 2001.

[13] United States Department of Energy, Environmental assessment for U-233 material downblending and disposition project at the Oak Ridge National Laboratory, DOE/EA-1651, 2010 .

[14] United States Environmental Protection Agency, Technology reference guide for radioactively contaminated media, Office of Radiation and Indoor Air Radiation Protection Program, EPA 402-R-07-004, 2007.

[15] United States Nuclear Regulatory Commission, Results of the license termination rule analysis of the use of intentional mixing of contaminated soil, SECY-04-0035, 2004. 